\title{
A OTSP E O RESGATE DA IMPRESSÃO TIPOGRÁFICA NO BRASIL
}

\author{
Rafael Neder \\ Universidade FUMEC \\ rafael@rafaelneder.com.br \\ Gisela Belluzzo de Campos \\ Universidade Anhembi Morumbi \\ gbcampos@anhembi.br
}

\begin{abstract}
Resumo: Este artigo faz um relato sobre a trajetória da Oficina Tipográfica São Paulo, desde sua criação em 2000 até o momento atual, enfatizando o pioneirismo no resgate da cultura e da tecnologia da impressão tipográfica. Com equipamentos apropriados e com o auxílio de profissionais capacitados para manipulá-los, os designers da OTSP abrem caminho para estudantes e jovens designers retomarem essas práticas em seus estudos e projetos, o que vem acontecendo a cada dia com mais intensidade, e colaboram para o enriquecimento da linguagem do design gráfico contemporâneo. $O$ texto foi construído a partir de entrevistas com os criadores da Oficina, da observação dos trabalhos realizados na OTSP, de artigos e depoimentos em revistas e de pesquisa bibliográfica em livros da área de design gráfico.
\end{abstract}

Palavras-chave: Oficina Tipográfica São Paulo; impressão tipográfica; linguagem gráfica; design gráfico; tipografia.

\section{INTRODUÇÃO}

Este texto é parte integrante da pesquisa para a dissertação de Mestrado "Práticas Contemporâneas da Impressão Tipográfica no Brasil" desenvolvida no Programa de PósGraduação em Design na Universidade Anhembi Morumbi no âmbito da linha de pesquisa "Design, Tecnologia e Linguagem: Interfaces". A dissertação como um todo analisa a produção de designers brasileiros que se utilizam da impressão tipográfica de modo a explorar as possibilidades expressivas dessa tecnologia. Dentro deste escopo destaca-se, como pioneira no resgate desta atividade no Brasil, a Oficina Tipográfica São Paulo (OTSP), formada inicialmente pelos designers Marcos Mello, Claudio Rocha e Claudio Ferlauto. $O$ texto traça um breve histórico do percurso da Oficina por considerá-la parte importante da história recente do nosso design gráfico e tece alguns comentários sobre a linguagem gráfica resultante desta atividade.

Na contemporaneidade, a valorização de uma prática tipográfica que incorpora técnicas manuais e mecânicas têm sido uma constante em várias partes do mundo. Jury 
(2006) observa que o retraimento da impressão tipográfica tem permitido nos últimos anos que designers e artistas gráficos interessados nas particularidades expressivas dessa tecnologia adquiram esses antigos equipamentos dando-lhes um novo fazer produtivo. Para Rocha (2011) o fato de muitos designers estarem voltando seu olhar e atenção para essas técnicas do passado, atesta a busca por uma materialidade que dificilmente pode ser emulada pela tecnologia digital. Drucker (1996) observa que pensar a materialidade do impresso gráfico evoca duas questões indissociáveis: a primeira é compreender a matéria em seu sentido literal, isto é, entender como a materialidade de um artefato é expressa pelos meios com os quais é feita, tornando-a assim tangível pelos nossos sentidos. A segunda é entendê-la como resultado de um processo cultural, como um registro das intenções, escolhas e valores de quem projetou o artefato.

O relato exposto neste artigo foi construído sobretudo por meio de entrevistas realizadas pelos autores com os atuais diretores da OTSP. A natureza qualitativa e o caráter exploratório da investigação fez com que se optasse pela utilização da metodologia da História Oral para a coleta e análise dos dados. A História Oral pode ser entendida como "um procedimento metodológico" capaz de "registrar, através de narrativas induzidas e estimuladas, testemunhos, versões e interpretações sobre a História em suas múltiplas dimensões" (DELGADO, 2010, p. 15). Dessa maneira foi possível registrar as diferentes visões individuais formalizando-as em documentos que por sua vez permitiram a identificação de temas relevantes a partir do entrecruzamento de informações. As entrevistas realizadas foram do tipo temático e optou-se por utilizar nas entrevistas um questionário semiestruturado, o qual foi dividido em quatro partes interrelacionadas, sem um ordenamento fixo para as perguntas (Quadro 1). O questionário apresentou a seguinte estrutura: na primeira parte, buscou-se identificar informações pessoais de cada entrevistado; na segunda parte, delimitar as origens do envolvimento do entrevistado com a tipografia e a impressão tipográfica; na terceira parte, o objetivo era compreender as diferentes dimensões relacionadas à prática profissional de cada um dos depoentes; na quarta e última parte foram apresentadas questões mais específicas, relacionadas à problematização da pesquisa da dissertação.

Quadro 1 - Roteiro geral utilizado durante as entrevistas.

\begin{tabular}{|l|l|}
\hline PARTES & QUESTÕES RELACIONADAS \\
\hline Identificação & Nome, idade, formação e profissão \\
\hline Tipografia & $\begin{array}{l}\text { Como define tipografia } \\
\text { Como se interessou pela tipografia } \\
\text { Como se envolveu com a impressão tipográfica }\end{array}$ \\
\hline $\begin{array}{l}\text { Prática e histórico } \\
\text { profissional }\end{array}$ & $\begin{array}{l}\text { Métodos de trabalho } \\
\text { Processo criativo } \\
\text { Influências e referências }\end{array}$ \\
\hline Problematização & $\begin{array}{l}\text { Como percebe as relações entre a tecnologia digital e a impressão tipográfica } \\
\text { Como percebe o futuro da impressão tipográfica }\end{array}$ \\
\hline
\end{tabular}

Fonte: Elaborado pelo autor, com base na pesquisa realizada

$\mathrm{Na}$ tentativa de garantir maior naturalidade dos entrevistados, os depoimentos foram realizados em seus respectivos locais de trabalho, uma vez que as entrevistas foram registradas em vídeo e com o apoio auxiliar de um gravador de som. Foi feito, ainda, um registro fotográfico da produção e dos locais de trabalho desses entrevistados. Sob essas condições, as entrevistas foram realizadas nos meses de junho e agosto de 2013. 
Posteriormente à gravação, passou-se ao processamento dos depoimentos, que foi subdividido em etapas distintas, mas complementares entre si. Primeiramente, foi realizada a transcrição das entrevistas, com o cuidado de reproduzir com fidelidade cada um dos depoimentos: buscou-se, assim, respeitar ao máximo as idiossincrasias e as características do vocabulário de cada entrevistado. Na etapa seguinte buscou-se, tomando por base os depoimentos transcritos, construir evidências a partir da análise qualitativa das entrevistas. Após a revisão dos depoimentos, buscou-se identificar os temas principais e as eventuais correlações a serem analisados no contexto da dissertação. Assim, na tentativa de compreender melhor as informações levantadas, foram criados três tipos de documentos: mapas mentais, planilhas cronológicas e quadros temáticos. Assim, ao combinar esses diferentes procedimentos foi possível a elaboração desse relato

\section{A OFICINA TIPOGRÁFICA SÃO PAULO}

\subsection{A Fundação}

Foi no ano 2000 que os caminhos dos designers Claudio Ferlauto, Claudio Rocha e Marcos Mello se entrecruzaram pela primeira vez. Naquele momento, Marcos cursava a especialização em Design Gráfico do Centro Universitário Belas Artes de São Paulo. Seu interesse por tipografia o aproximou de Claudio Ferlauto, que era docente naquela instituição e há muitos anos amigo de Claudio Rocha, que na época preparava uma reportagem sobre grafite e pichação para a primeira edição da revista Tupigrafia. Sabendo do interesse e envolvimento de Marcos Mello com o tema, Ferlauto o apresentou para Claudio Rocha, que convidou Mello para colaborar com a revista e a partir de então os interesses comuns estreitaram os laços entre os três designers, originando novos projetos em parceria.

O interesse comum pela impressão tipográfica fez com que os três adquirissem, esparsamente, entre os anos de 2000 e 2003, algumas gavetas de tipos e outros equipamentos, como um prelo tira-provas. Porém, a primeira grande compra aconteceu somente em 2003, quando, por indicação de conhecidos, chegaram à Nenê Artes Gráficas, uma pequena tipografia localizada no bairro de Vila Matilde, Zona Leste de São Paulo. 0 proprietário, Seu Nenê, era um migrante que chegara à cidade muitos anos antes e que, naquele momento, desejava se aposentar e retornar à sua cidade natal. Por esse motivo Seu Nenê estava vendendo sua gráfica e dele os três amigos compraram uma impressora Minerva Formato 4, uma guilhotina manual e dois cavaletes de tipos.

Dessa conjunção entre máquinas e homens, surge a ideia de criar um espaço capaz de reconectar o passado e o presente da tecnologia gráfica para então repensar o futuro do design gráfico e assim, no segundo semestre de 2003 (FIG. 1), nasce a Oficina Tipográfica São Paulo (OTSP). A escolha do nome não poderia ser mais adequada: dentre as diferentes acepções do termo oficina, destaca-se o entendimento de um lugar onde se exerce um ofício, onde se constrói ou se conserta algo, e também de um lugar onde se verificam grandes transformações (CUNHA, 1982; FERREIRA, 2004; HOUAISS; VILLAR; FRANCO, 2001).

Naquele ano, instalam provisoriamente o acervo nos fundos da Alves Artes Gráficas onde Marcos Mello trabalha como gerente e, aos poucos, a coleção de máquinas e tipos aumenta. Ainda em 2003 compram uma Linotype Modelo 31 do linotipista aposentado Gonçalo Gimenes, fabricada nos Estados Unidos e importada para o Brasil nos 
anos 1940 que havia sido utilizada no jornal Diário Popular (atual Diário de São Paulo) onde Gonçalo foi linotipista até o início dos anos 1980 quando rescindiram seu contrato de trabalho. A máquina Ihe foi entregue como parte de sua indenização trabalhista o que permitiu que ele abrisse sua própria linotipadora e assim prestasse serviços de composição linotípica para outras gráficas. Como já não era utilizada há muitos anos e necessitava de reparos, o conserto do equipamento fica à cargo do Sr. Adão Alegre, linotipista e instrutor aposentado do SENAI que ao longo de dois meses efetua os reparos necessários para que a máquina entre novamente em funcionamento (TUPIGRAFIA, 2004). Com o auxílio do impressor Valter José Gonçalves, produzem os primeiros materiais promocionais da OTSP, dentre eles um conjunto de 10 envelopes, selecionados no ano seguinte para a "7a Bienal de Design Gráfico da ADG" e para a mostra "Brasil Faz Design 2004" (FIG. 2).

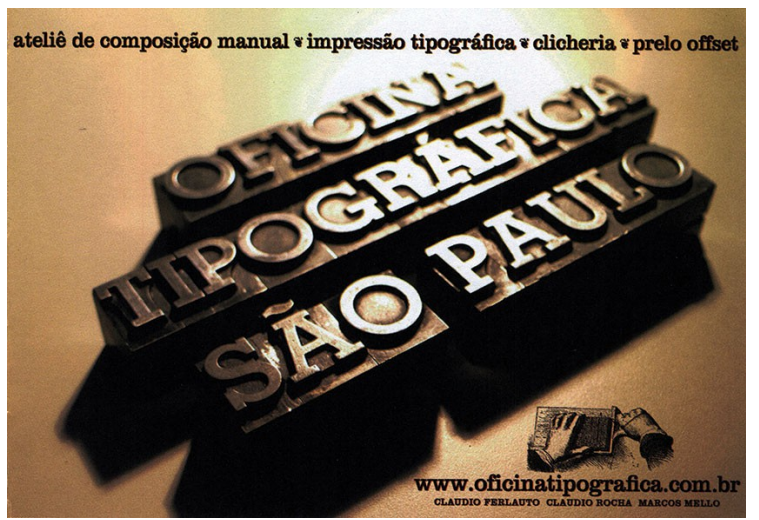

Figura 1 - Primeiro anúncio da OTSP publicado em outubro de 2003 na revista Tupigrafia no 4.

Fonte: TUPIGRAFIA, 2003, p. 67.
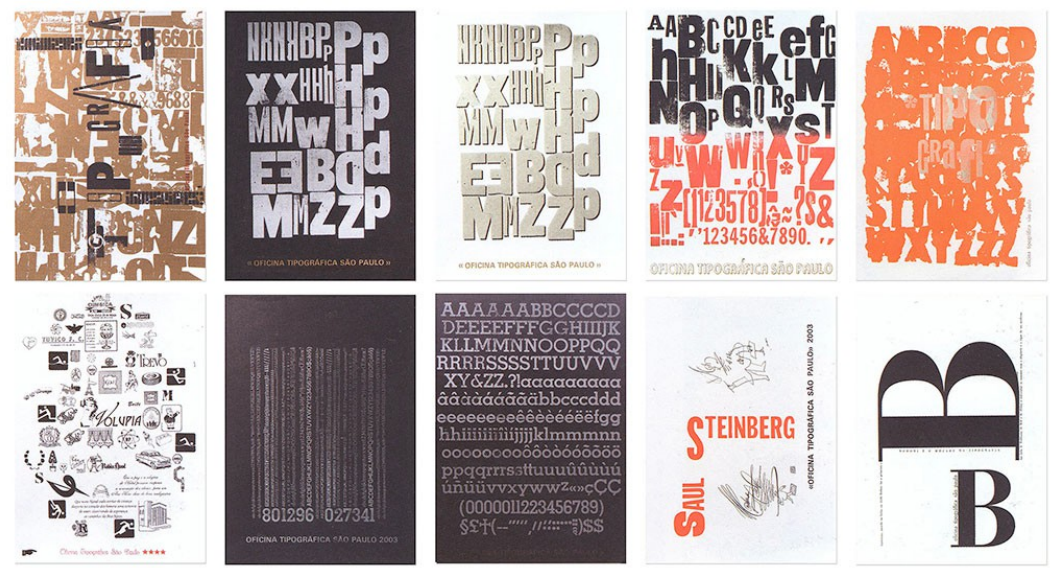

Figura 2 - Série de envelopes para a Oficina Tipográfica São Paulo.

Fonte: ASSOCIAÇÃO DOS DESIGNERS GRÁFICOS DO BRASIL, 2004, p. 311.

Após alguns meses de preparação, em 14 de fevereiro de 2004, a Oficina é aberta ao público (FIG. 3) e nos meses seguintes acontecem os primeiros cursos. Os atendimentos aos visitantes intercorrem com hora marcada e normalmente em horários ociosos da gráfica.

Em julho de 2004, publicam um breve manifesto encartado na quinta edição da revista Tupigrafia (FIG. 4) por meio do qual apresentam a Oficina para os leitores da publicação e para a comunidade do design gráfico em geral. Com o provocativo título "Uns 
Caras Loucos na Contramão?" logo de início argumentam a respeito da necessidade de preservar a técnica no contexto contemporâneo:

\begin{abstract}
[Uns caras loucos na contramão?] Sim, é o que pode parecer. No vertiginoso fluxo da tecnologia da computação gráfica a palavra de ordem é trilhar o inimaginável, sempre com os olhos no futuro. Mas esse também é o caminho da Oficina Tipográfica São Paulo. Afinal, o passado está presente no futuro. Ou ao contrário. Portanto, olhar para trás, buscando o resgate da linguagem visual do antigo sistema de impressão tipográfica e inseri-la como um recurso de estilo dentro do universo digital não é nenhum absurdo (OFICINA TIPOGRÁFICA SÃO PAULO, 2004, p.109).
\end{abstract}

No texto explicam as diretrizes iniciais da OTSP. Primeiramente definem a Oficina como um espaço dedicado à preservação da cultura material e imaterial da tipografia e expressam o objetivo de torná-la uma gráfica experimental capaz de combinar a tecnologia da impressão tipográfica com as ferramentas da tecnologia digital para a criação de produtos gráficos diferenciados. Assim, para alcançar essas metas, definem como estratégia a prática de cursos e a perspectiva de produzirem projetos sob encomenda.
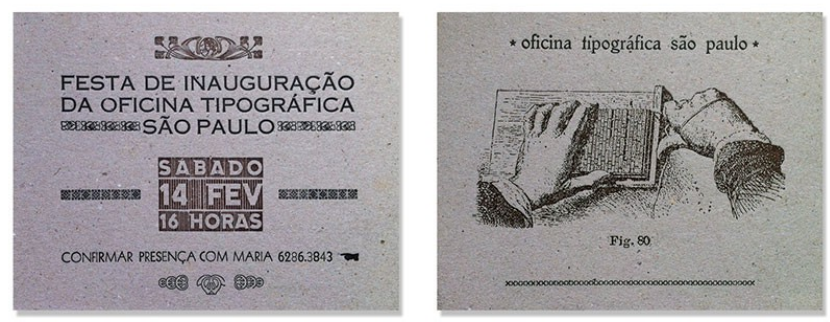

Figura 3 - Convite para a inauguração da Oficina Tipográfica São Paulo. Impresso em $2 \times 2$ cores, em papelão calandrado $500 \mathrm{~g} / \mathrm{m} 2$ no formato de $17,9 \times 13,8 \mathrm{~cm}$. Projeto gráfico de Claudio Rocha, Claudio Ferlauto e Marcos Mello. Impressão de Valter José Gonçalves.

Fonte: Fotografias de Henrique Nardi.
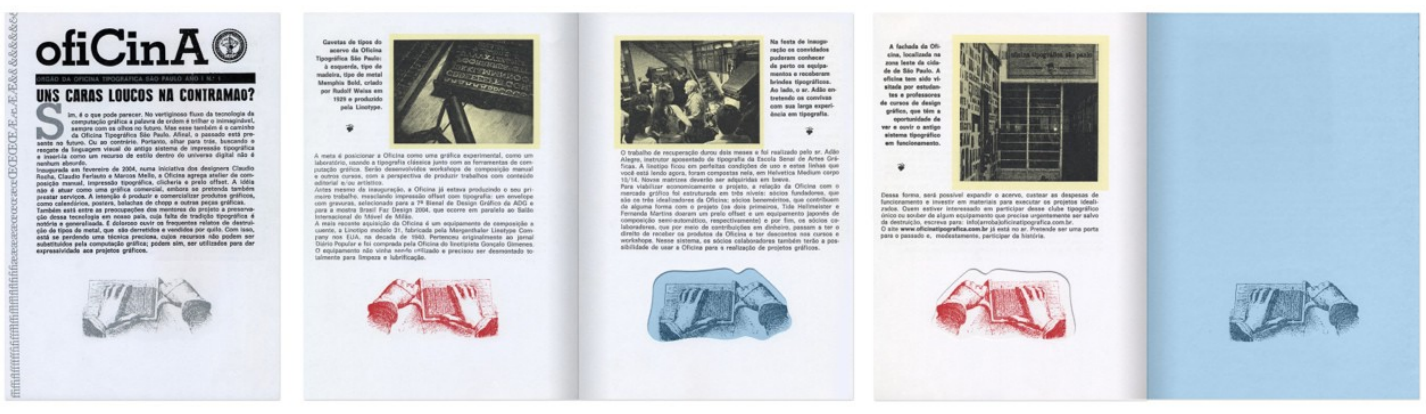

Figura 4 - As cinco primeiras páginas do encarte da OTSP na Tupigrafia 5.

Fonte: Fotografias do acervo de Rafael Neder.

\title{
2.2 A preservação por meio do ensino e da pesquisa
}

Em seu primeiro ano de atividades a OTSP funciona de maneira informal, porém essa situação precisou ser revista quando Marcos Mello optou por se desligar da empresa onde a Oficina ficava hospedada. A necessidade de encontrar um local apropriado para o acervo fez com que procurassem o Prof. Manoel Manteigas, diretor da Escola SENAI Theobaldo de Nigris, que demonstrou interesse em firmar um convênio com a OTSP, porém antes seria necessário registrar a Oficina como uma Organização Não Governamental e assim, em 2005, foi realizado o convênio com o SENAI. O acordo permite 
que a Oficina consolide suas atividades de preservação e pesquisa e adquira novos equipamentos que chegam com compras e doações, e com isso a OTSP também fica responsável por gerir o acervo da escola composto de mobiliário, fontes e impressoras. Ao longo do biênio 2005-2006 realiza-se a montagem e a organização da nova oficina nos galpões do SENAI. Durante esse período de transição Claudio Ferlauto se desliga da direção da Oficina por motivos profissionais.

No início de 2007, com a Oficina devidamente instalada, Marcos Mello e Claudio Rocha estabelecem as novas diretrizes para o funcionamento da OTSP. Com o apoio e a infraestrutura do SENAI é possível ampliar e consolidar as atividades de ensino e pesquisa. Sistematizam três módulos de cursos complementares sendo os dois primeiros sobre impressão tipográfica e o terceiro sobre encadernação artesanal. O primeiro módulo dos cursos, chamado de Composição Introdutória, tem como objetivo apresentar aos participantes os fundamentos da composição manual e do pensamento projetual da impressão tipográfica. Para tanto, os alunos projetam um cartão de visitas no formato de $9 \times 5 \mathrm{~cm}$, impresso frente e verso, e em até duas cores. Além dos tipos móveis os estudantes também têm uma breve demonstração da composição à quente. Cada estudante tem seu e-mail composto pela máquina podendo ou não utiliza-lo em seu cartão de visitas. O segundo módulo, incialmente chamado de Cartaz Tipográfico e hoje denominado Gravura Tipográfica, busca investigar as possibilidades expressivas da impressão tipográfica por meio do projeto de um cartaz. O formato utilizado para a produção dos cartazes é de $33 \times 48 \mathrm{~cm}$ podendo ser impressos em uma ou duas cores. Neste módulo os alunos tem um contato maior com os tipos de madeira devido a dimensão escolhida para o pôster. No terceiro módulo, Técnicas de Encadernação para Designers, embora o foco esteja na encadernação artesanal, a impressão tipográfica também se faz presente ainda que de maneira indireta. Além de aprender algumas costuras básicas para a produção de protótipos ou pequenas tiragens de livros, os alunos do módulo utilizam sobras e malas de impressão tipográfica da OTSP para a confecção das capas dos livros feitos durante a oficina. Em ambos os cursos os alunos são encorajados a pensar e a questionar sobre a validade dos conhecimentos adquiridos e sua aplicabilidade no contexto do design gráfico contemporâneo. Ao longo dos anos estes cursos vem se transformando em um importante meio para obtenção de recursos para a ONG permitindo assim sua existência.

Para celebrar essa nova etapa, iniciam também a produção do álbum de gravuras "Além da Letra" (FIG. 5). A direção de criação do projeto é assinada por Claudio Rocha, com design de Marcos Mello e Marina Chaccur, designer que junta-se à equipe da OTSP em junho daquele ano para auxiliar na produção do livro e na condução dos cursos, uma vez que Claudio Rocha se muda temporariamente para Gênova na Itália no segundo semestre de 2007. Chaccur, graduada em design gráfico na Fundação Armando Alvares Penteado e mestre em Design Gráfico no London College of Communication, dedica-se neste momento ao estudo e prática da tipografia. Ao longo do segundo semestre de 2007 Marcos e Marina, com o auxílio do linotipista Adão Alegre e dos tipógrafos Valter José Gonçalves e Pérsio Prado Guimarães, trabalham na impressão do álbum.

No mesmo período, Marina também leciona com Marcos Mello nos cursos e projeta alguns materiais promocionais da OTSP e finalmente, desliga-se da oficina em janeiro de 2008. Assim, entre 2008 e 2010, no período em que Claudio esteve ausente, Marcos Mello conduz os cursos sozinho. 


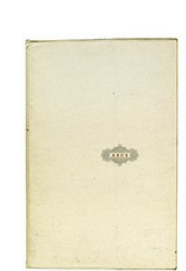

A

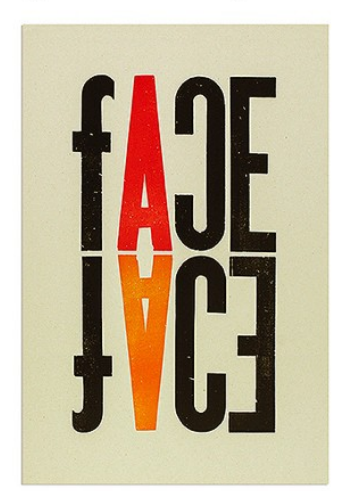

C

B
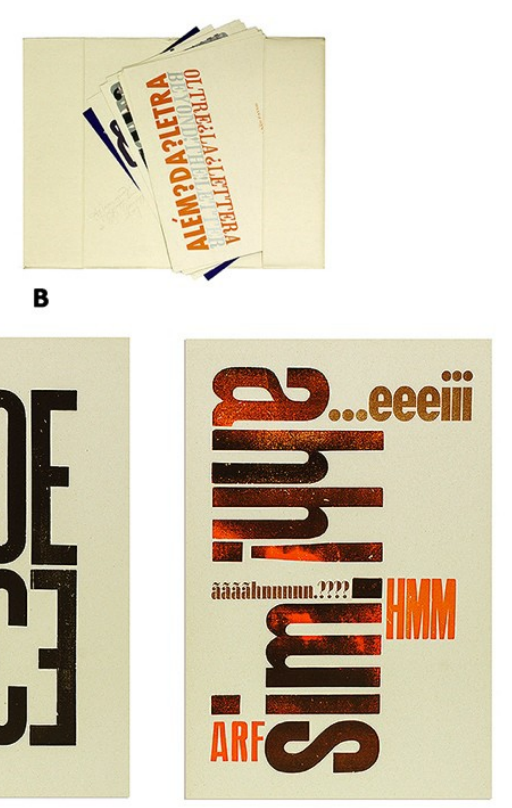

D

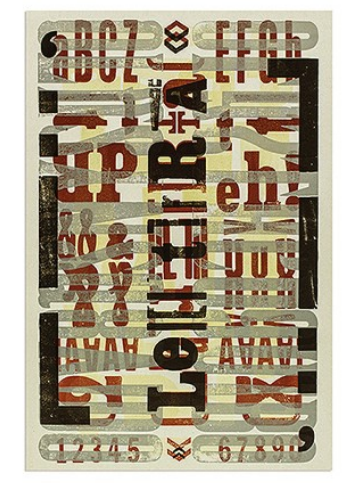

E

Figura 5 - Além da Letra. Pasta com 51,8 $\times 34,5 \mathrm{~cm}$, impressa em duas cores, com dois bolsos internos e costuradas pelas bordas. 0 miolo por sua vez tem dimensões de $33 \times 47 \mathrm{~cm}$ e é formado por 18 lâminas sendo 16 gravuras tipográficas identificadas com seus respectivos títulos no verso de cada lâmina. Pasta e miolo impressos em papel Reciclato $240 \mathrm{~g} / \mathrm{m}^{2}$ A) Pasta fechada. B) Pasta aberta com o miolo saindo de um dos bolsos. C)“Espelhamento Irregular” E)“Expressões Casuais” E) “Virada”.

Fonte: Fotografias do acervo de Rafael Neder.

Com o encerramento da editora Bookmakers, a revista Tupigrafia passa a ser publicada pela Oficina Tipográfica São Paulo em 2007. Essa transição era esperada uma vez que a publicação fora idealizada conjuntamente por Claudio Rocha e o designer Tony de Marco, ambos os editores da revista. Deste modo em março de 2007 lançam a sétima edição da Tupigrafia pela OTSP. A parceria com o SENAI permite que a revista seja impressa pelos alunos e professores dos cursos da Print Media Academy de São Paulo, um programa de treinamento conduzido em parceria com a fabricante alemã de maquinário e insumos gráficos Heidelberg. Observa-se que desde a criação da OTSP, essa proximidade temática fez com que ela participe da revista desde seu primeiro momento e de diferentes maneiras: anúncios, reportagens, encartes e cartazes para a revista.

Durante o período na Itália, Claudio Rocha mantem o vínculo com a Oficina e a Tupigrafia, porém a distância faz com que a velocidade de lançamento de novos projetos no Brasil seja significativamente reduzida. Nesse período Rocha estabelece uma série de conexões importantes no exterior, onde realiza, entre os anos de 2008 e 2009, diferentes palestras sobre a OTSP na Itália ${ }^{1}$ e na Inglaterra ${ }^{2}$, e se aproxima de muitos designers e artistas interessados em tipografia. No segundo semestre de 2008, juntamente com a alemã radicada na Itália Simone Wolf, publica a revista Tipoitalia. A revista, que segue a linha editorial da brasileira Tupigrafia, tem apenas duas edições, sendo que na segunda edição, a impressão tipográfica é utilizada em dois encartes produzidos por designers e impressores italianos convidados.

Em agosto de 2008, devido a passagem de Claudio Rocha pelo Brasil, realizam o lançamento da oitava edição da Tupigrafia. Para a revista, a Oficina produz um encarte

\footnotetext{
1 "Tipografia brasiliana allo IED di Milano". Disponível em: <http://www.aiap.it/notizie/10231>. Acesso em 1 Abr. 2014.

2 "Revival”. Disponível em: <http://stbride.org/events/revival/programme>. Acesso em 1 Abr. 2014.
} 
de oito páginas como parte integrante de uma matéria sobre poesia visual. No texto os editores expressam o desejo de "revisitar poemas em que a forma e o olhar se somam à poética" e por meio da composição tipográfica dar ao texto "uma outra expressão" e concluem desafiando os leitores para que ouçam "com os olhos" ${ }^{3}$, e assim além de interpretarem poemas de autores consagrados - como Augusto de Campos apresentam outros textos de designers e artistas visuais (FIG. 6).
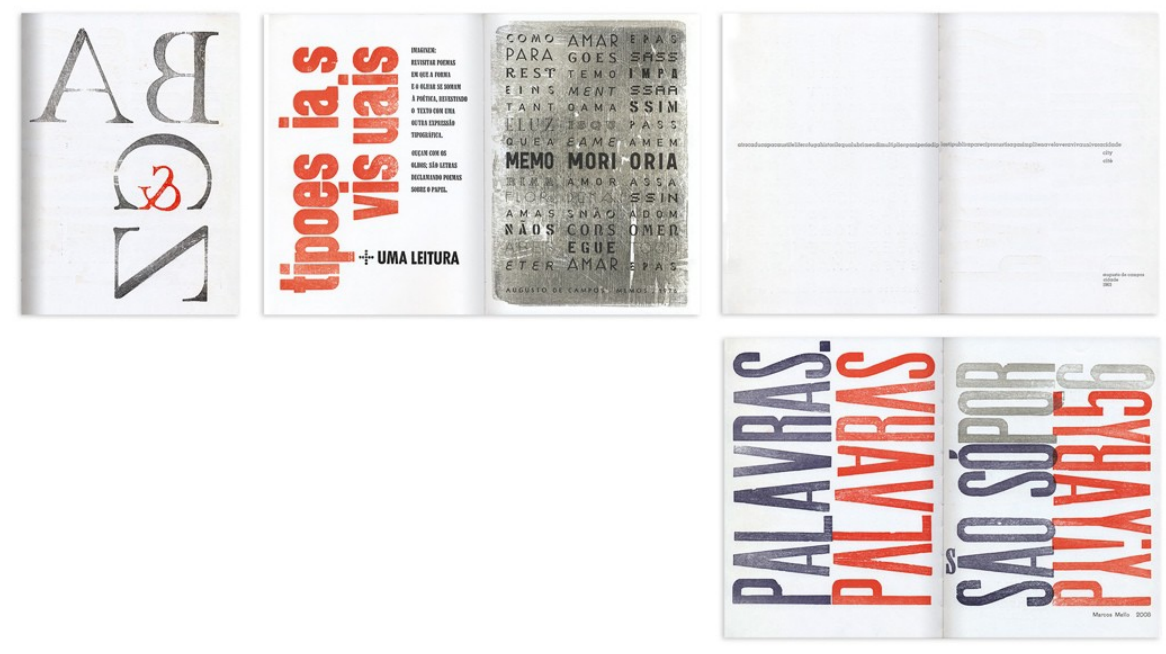

Figura 6 - Encarte da OTSP na revista Tupigrafia 8.

Fonte: Fotografia do acervo de Rafael Neder.

No primeiro semestre do ano seguinte, a Oficina Tipográfica São Paulo inicia "2009 OTSP" um calendário com gravuras dos diretores da Oficina e de artistas convidados. Com Claudio na Itália e Marcos em São Paulo as tarefas são divididas, o primeiro fica responsável pelo projeto gráfico e o segundo pela impressão e produção gráfica, já a escolha e o contato com os artistas foi feita por ambos. Uma das características do álbum está relacionada à diversidade de materiais utilizados na fabricação das matrizes de impressão e que se faz presente na expressividade gráfica do calendário. Além de clichês de fotopolímero foram utilizadas madeira, MDF, tipos móveis, Recouro (couro reconstituído) e outros materiais. $O$ resultado foi acondicionado em uma caixa no formato de $49,5 \times 33,5 \mathrm{~cm}$, feita de papel cartão revestido e com o título do calendário impresso com verniz UV no centro da caixa. $\mathrm{O}$ calendário por sua vez tem o formato de $47 \times 33 \mathrm{~cm}$, com encadernação Wire-O na parte superior, totalizando 15 lâminas, sendo 12 delas com gravuras coladas manualmente nas respectivas folhas (FIG. 7). Nesse projeto a impressão foi realizada por Pérsio Guimarães e Marcos Mello, o que mostra um aprofundamento significativo deste último nas nuances técnicas do processo. Aproveitando a passagem de Claudio Rocha pelo Brasil, o calendário é lançado no dia 16 de Junho de 2009 no espaço Finepapers no Cambuci e as gravuras expostas no período de 17 de junho à 17 de setembro naquele mesmo local. A exposição que recebeu o nome "Matriz Papel Gravura" teve projeto expográfico assinado por Marcos Mello, Tatiane de Feó e Bruno Jancowisk.

\footnotetext{
${ }^{3}$ OFICINA TIPOGRÁFICA SÃO PAULO, 2008, p.2
} 

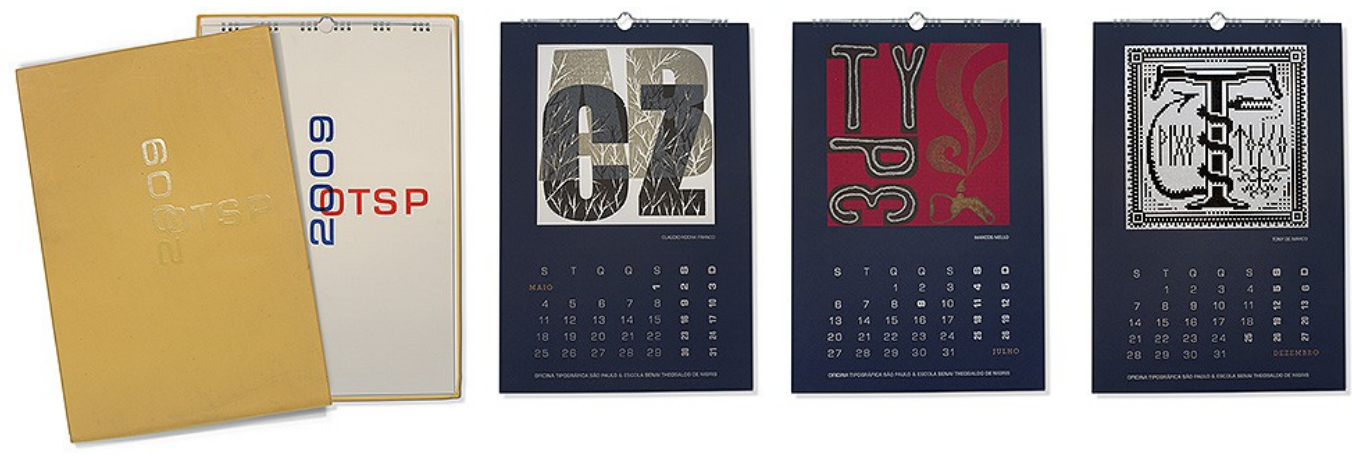

Figura 7 - Da esquerda para a direita: Estojo e capa de 2009/OTSP; xilogravura de Claudio Rocha; cologravura e tipos móveis de Marcos Mello e gravura em fotopolímero de Tony de Marco.

Fonte: Fotografia do acervo de Rafael Neder.

Em agosto de 2009 a OTSP lança oficialmente o álbum "Além da Letra". Embora a publicação tenha sido produzida anos antes, ela não havia sido lançado em razão da mudança de Claudio para a Itália, e assim sob um pretexto duplo, a presença de Claudio Rocha e os cinco anos da oficina, lançaram o álbum em 22 de agosto de 2009 (FIG. 8).

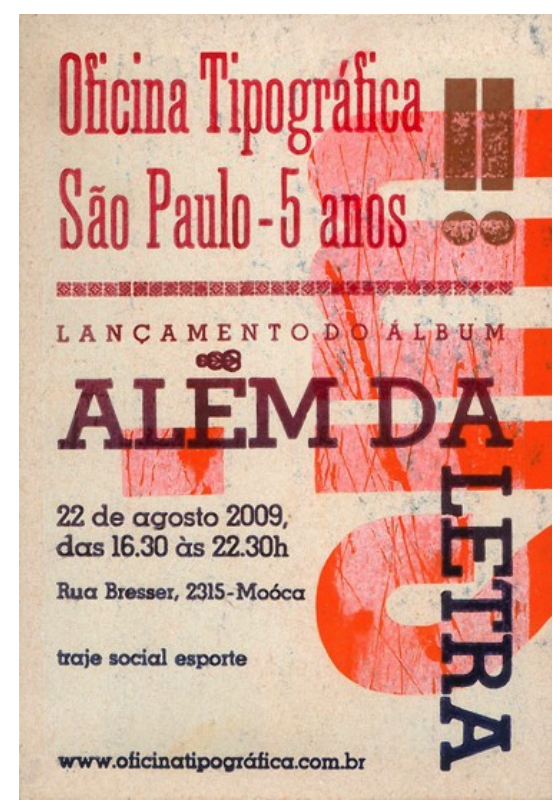

Figura 8 - Convite de lançamento de "Além da Letra". Impresso em papel Reciclato $240 \mathrm{~g} / \mathrm{m}^{2}$ sobre malas de impressão do álbum e no formato de $16 \times 23,5 \mathrm{~cm}$.

Fonte: Fotografia do acervo de Rafael Neder.

Em 2010, com o retorno de Claudio para o Brasil, antigos projetos são retomados e novos ideias começam a ser desenvolvidas pela OTSP. Ao longo dos anos a coleção de tipos da Oficina cresceu significativamente, com a tutela do acervo do SENAI e a incorporação de novos tipos foi necessário iniciar a catalogação dessa coleção de fontes, coube então a Rocha realizar essa tarefa nos primeiros meses do ano. No mesmo período Claudio volta a participar do cotidiano dos cursos da Oficina assumindo o segundo módulo dos cursos. Em maio de 2010 a OTSP publica a nona edição da Tupigrafia e para o lançamento da revista produzem um cartaz no formato de $48 \times 33$ $\mathrm{cm}$, impresso em duas cores na OTSP (FIG. 9). O lançamento aconteceu como parte da programação de um evento no Instituto Europeu de Design. 


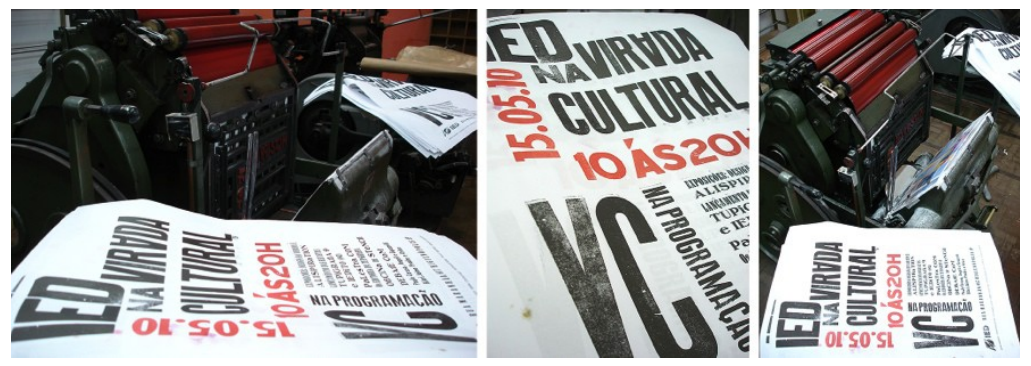

Figura 9 - Imagens da produção do cartaz do lançamento da revista Tupigrafia 9.

Fonte: Disponível em: <https://www.flickr.com/photos/otsp/>. Acesso 1. Abr. 2014.

Entre 2010 e 2012, a Oficina tipográfica realiza uma série de trabalhos em parceria com outros artistas e instituições dentre eles o álbum "Wood Type Metal Color" criado por Claudio Rocha para a fabricante de papéis Arjo Wiggins. A publicação é composta por 10 cartazes formato $\mathrm{A} 2$, impressos manualmente em diferentes papéis da linha Metal Color, com tiragem restrita à 20 exemplares numerados foi lançada em maio de 2011.

Para a décima edição da revista Tupigrafia de Abril de 2012, a OTSP cria um encarte de 8 páginas sobre a fonte Block do alemão Hermann Hoffman (1856-1926). Nele utilizam tipos doados pelo SESC/Pompéia e acompanhados de um clichê para a reprodução de ornamentos também do início do século XX. A direção de arte da matéria é assinada por Cláudio Rocha e o encarte impresso conjuntamente por Pérsio Guimarães e Alexandre Lopes, este último aprendiz e monitor dos cursos da OTSP (FIG 11).
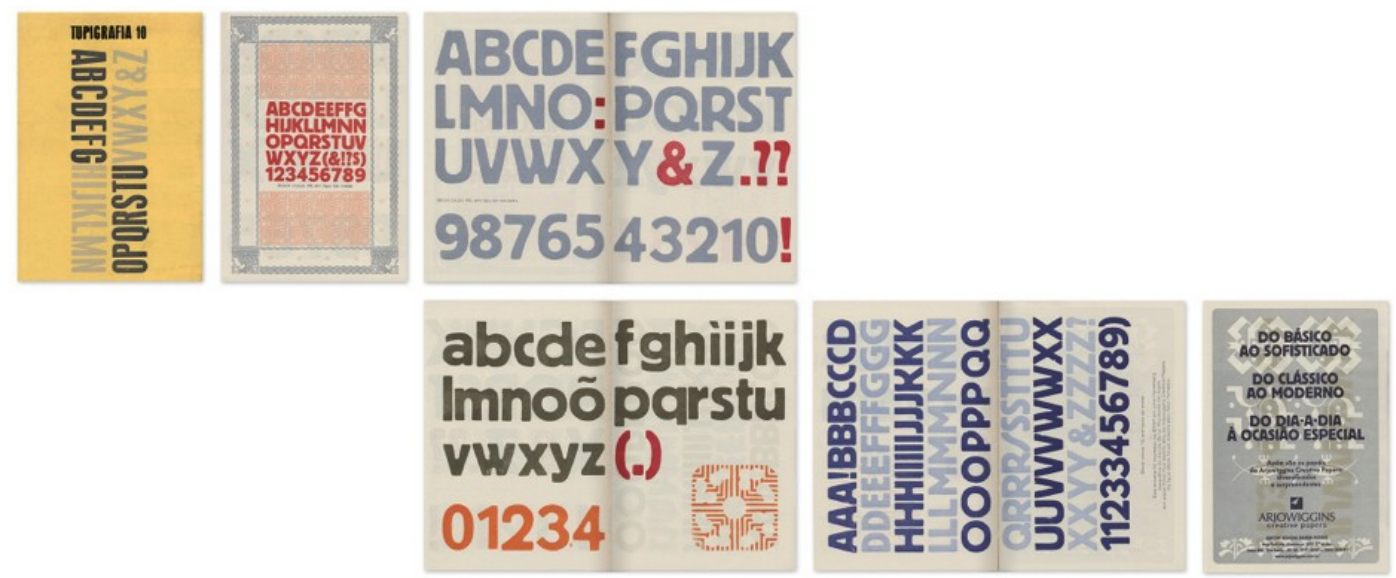

Figura 10 - Encarte da OTSP na revista Tupigrafia $\mathrm{n} \div 10$.

Fonte: Fotografia do acervo de Rafael Neder.

Para a Fundação Bienal de São Paulo, criam em conjunto com o designer André Stolarski o livro "Linha do Tempo da Bienal". Publicado no segundo semestre de 2012 o livro se caracteriza pelo formato sanfona e pela combinação dos processos da impressão tipográfica com o offset tradicional e digital.

Em 2013, suspendem temporariamente os cursos na Oficina e durante esse hiato avaliam os resultados alcançados e definem novos objetivos. $O$ amadurecimento profissional e sucesso da OTSP permitiu que no período de 2011 e 2013, Marcos Mello e Claudio Rocha desenvolvem-se uma série de atividades paralelas, porém de alguma forma ligadas à OTSP. 


\subsection{Além da Oficina}

Com o aumento da demanda por projetos comerciais e desvinculados da proposta inicial da Oficina, Marcos Mello e sua esposa Patrícia Passos criam em 2011 a "Letterpress Brasil" um estúdio de design especializado em impressão tipográfica e já em seu primeiro ano de atividades atendeu clientes interessados na plasticidade da impressão tipográfica.

Entre os anos de 2012 e 2013, Claudio Rocha se dedica ao aperfeiçoamento de sua linguagem artística produzindo intensamente monotipias feitas com matrizes tipográficas e realiza diferentes exposições. Entre maio e junho de 2012 realiza a mostra "Monotipias Tipográficas" e entre outubro e dezembro de 2012 "Inconsequência Alfabética", ambas no ateliê Priscila Mainieri. Entre outubro de 2012 e janeiro de 2013, apresenta em parceria com a ABER (Associação Brasileira de Encadernação e Restauro) a mostra Inconsequências Alfabéticas, na Biblioteca do MASP. E novamente no ateliê Priscila Mainieri realiza entre novembro e dezembro de 2013 a mostra "Cartilha Tipográfica".

\subsection{A linguagem gráfica da Oficina Tipográfica São Paulo}

Os trabalhos da OTSP são caracterizados, dentre outros recursos, pelos detalhes requintados e inusitados, pelo uso da letra como imagem, pela experimentação em vários níveis com tipos de encadernação, formatos, papéis e tintas e pela exploração de recursos gráficos obtidos pelo próprio maquinário para obtenção de texturas e relevos. No álbum "Além da letra" (FIG. 6), o formato escolhido valoriza tanto a técnica quanto a linguagem dos tipos móveis ao aproximar a impressão tipográfica da gravura artística. A pasta faz as vezes de uma sobrecapa e nela encontra-se impressa em prata uma pequena borda arredondada semelhante a um camafeu, contendo em seu interior o texto "A B C Z" impresso em laranja na fonte Memphis corpo 36. No álbum, os designers investigam o aspecto icônico das letras explorando a materialidade dos tipos móveis e da impressão tipográfica. Em "Espelhamento Irregular", o verbal encontra o visual por meio da rotação dos tipos e do uso da cor, colocando em questão os dogmas da leiturabilidade e explorando a geometria das capitulares. Em "Expressões Casuais" a materialidade dos tipos de madeira é evidenciada por meio de uma sobreposição de cores onde intencionalmente a cor escura é impressa sem a pressão adequada criando uma textura visual que reforça essa expressão de casualidade do texto. Em "Virada", quatro matrizes são impressas de maneira sobreposta fazendo uma alusão ao movimento do impressor ao operar a máquina. No convite de lançamento de "Além da Letra" (FIG. 9) para melhorar a leiturabilidade do texto que foi impresso sobre malas de impressão, em cada lâmina foi impressa uma textura em branco ligeiramente opaca. Ao trazer as malas de trabalhos antigos para novos impressos valorizam a importância do fazer da impressão revelando o processo e questionando os limites da leiturabilidade do texto tipográfico. Em "2009 OTSP" (FIG. 8) o anacronismo da impressão tipográfica frente aos meios de produção da contemporaneidade é questionado em um calendário. Em "ABCZ" Claudio Rocha resgata letras caixa utilizadas em sinalização e grava sobre elas um conjunto de ranhuras que aludem à marcas de deteriorização do tempo. Em "TYPE" Mello discute a materialidade das matrizes combinando tipos móveis, barbantes, um abridor de metal e folhas de lixa para a impressão de sua gravura. Em ambas as gravuras percebem-se escolhas que questionam os materiais e as técnicas tradicionais da gravura artística. Nos encartes para as diferentes edições da Tupigrafia reforçam o caráter artesanal e o valor expressivo da impressão tipográfica colocando-a em contraponto com a impressão ofsete do restante da 
revista. Porém mostram a importância dessa reconciliação entre a antiga técnica ao combinar os processos.

\section{CONCLUSÃO}

O estudo da OSTP mostra-se relevante por identificar e contemplar uma tendência bastante presente no design contemporâneo que é o hibridismo de linguagem, de procedimentos e de recursos técnicos. A Oficina se destaca neste contexto como uma das iniciativas pioneiras no resgate de técnicas e equipamentos tradicionais de impressão gráfica e na reinserção de práticas manuais e mecânicas relacionadas à tipografia no Brasil, atividades que vêm conquistando a cada dia mais adeptos e vêm de encontro a uma ampliação do espectro do design gráfico contemporâneo e da prática tipográfica. Preservar esse tipo de cultura gráfica é importante no contexto do design de todos os tempos: a coexistência de técnicas, linguagens, procedimentos e fazeres de tempos e espaços distintos é um sintoma de maturidade e colabora para o enriquecimento da área.

\section{REFERÊNCIAS}

ASSOCIAÇÃO DOS DESIGNERS GRÁFICOS DO BRASIL. 7ạ Bienal de Design Gráfico. São Paulo: ADG - Associação dos Designers Gráficos do Brasil, 2004.

CUNHA, Antônio Geraldo da. Dicionário etimológico nova fronteira da língua portuguesa. Rio de Janeiro: Nova Fronteira, 1982.

DELGADO, Lucília de Almeida Neves. História Oral: memória, tempo, identidades. Belo Horizonte: Autêntica, 2010.

DRUCKER, Johanna. The Visible Word: Experimental Typography and Modern Art, 1909-1923. Chicago: University of Chicago Press, 1996.

FERREIRA, Aurélio Buarque de Holanda. Novo dicionário Aurélio da língua portuguesa. Curitiba: Positivo, 2004.

FUNDAÇÃO BIENAL DE SÃO PAULO. Rede de tensão: Bienal 50 anos. São Paulo: Fundação Bienal de São Paulo, 2001.

HOUAISS, Antonio; VILLAR, Mauro; FRANCO, Francisco Manoel de Mello. Dicionário Houaiss da Língua Portuguesa. Rio de Janeiro: Objetiva: Instituto Antônio Houaiss de Lexicografia, 2001.

JURY, David. Lettepress: New applications for traditional skills. Rotovision, 2006.

MELLO, Marcos. Marcos Mello: Depoimento [16 Ago. 2013]. Entrevistador: Rafael Neder. São Paulo, 2013. DVD (1h 30min).

OFICINA TIPOGRÁFICA SÃO PAULO. [Anúncio]. Out. 2003. Impressão offset em policromia, $16 \times 11$ cm. In: Tupigrafia. São Paulo, n. 4 , p. 67, Out. 2003.

Tupigrafia. São Paulo, n. 4, Out. 2003.

. São Paulo, n. 5, Jul. 2004.

São Paulo, n. 8, Ago. 2008.

São Paulo, n. 10, Abr. 2012.

ROCHA, Claudio. Além da Letra. São Paulo: Oficina Tipográfica São Paulo, 2007.

. Materialidade Digital. In: CAMPOS, Gisela Belluzzo de; LEDESMA, María. Novas

Fronteiras do Design Gráfico. São Paulo: Estação das Letras e Cores, 2011. p. 151-157. Claudio Rocha: Depoimento [18 Jul. 2013]. Entrevistador: Rafael Neder. São

Paulo, 2013. DVD (1h 30min). 